\title{
Oxidative stress protection by newly synthesized nitrogen compounds with pharmacological potential
}

\author{
João P. Silva ${ }^{\mathrm{a}}$, Filipe M. Areias ${ }^{\mathrm{b}}$, Fernanda M. Proença ${ }^{\mathrm{b}}$, Olga P. Coutinho, ${ }^{\mathrm{a}}{ }^{\text {* }}$ \\ ${ }^{a}$ Department of Biology, Campus de Gualtar, University of Minho, 4710-057 Braga, Portugal \\ ${ }^{b}$ Department of Chemistry, Campus de Gualtar, University of Minho, 4710-057 Braga, Portugal
}

*Corresponding author, Tel. +351-253-604317; fax +351-253-678980

E-mail address: olgapc@bio.uminho.pt (O. P. Coutinho)

\begin{abstract}
In this study we used new nitrogen compounds obtained by organic synthesis whose structure predicted an antioxidant potential and then an eventual development as molecules of pharmacological interest in diseases involving oxidative stress. The compounds, identified as FMA4, FMA5, FMA7 and FMA8 differ in the presence of hydroxyl groups located in the C-3 and/or C-4 position of a phenolic unit, which is possibly responsible for their free radicals buffering capacity. Data from the DPPH discoloration method confirm the high antiradical efficiency of the compounds. The results obtained with cellular models (L929 and PC12) show that they are not toxic and really protect from membrane lipid peroxidation induced by the ascorbate-iron oxidant pair. The level of protection correlates with the drugs lipophilic profile and is sometimes superior to trolox and equivalent to that observed for $\alpha$-tocopherol. The compounds FMA4 and FMA7 presented also a high protection from cell death evaluated in the presence of a staurosporine apoptotic stimulus. That protection results in a significant reduction of caspase-3 activity induced by staurosporine which by its
\end{abstract}


turn seems to result from a protection observed in the membrane receptor pathway (caspase-8) together with a protection observed in the mitochondrial pathway (caspase-9). Taken together the results obtained with the new compounds, with linear chains, open up perspectives for their use as therapeutical agents, namely as antioxidants and protectors of apoptotic pathways. On the other hand the slight prooxidant profile obtained with the cyclic structures suggests a different therapeutic potential that is under current investigation.

Keywords: nitrogen compounds; antioxidants; lipid peroxidation; oxidative stress; cell apoptosis. 


\section{Introduction}

It is nowadays well established that several pathologies, namely at the central nervous system and/or cardiovascular level are clearly related with oxidative stress (Lovell et al., 1995; Pereira and Oliveira, 1997; Behl, 1999; Schroeter et al., 2000; Jang and Surh, 2001). The reactive oxygen species (ROS) are directly produced by exposition to chemicals or ionizing radiation, but also by drug metabolism or simply by normal cell metabolism, disturbing the cells natural antioxidant defence systems. From this disturbance results a damage to all of the major classes of biological macromolecules, including nucleic acids, proteins and lipids (Markesbery, 1997; Miranda et al., 2000; Nordberg and Arner, 2001). Furthermore, the formation of ROS and the intracellular alterations resulting from its action depends on the equilibrium state between oxidant and antioxidant components. So, in the last few years, several research groups have been focused in the search of substances that potentially can act as free radical scavengers, that is, that can act beyond the cells' natural defence systems (Bonnefont et al., 1998; Pereira

et al., 1999; Lebeau et al., 2000; German and Walzem, 2000; du Toit et al., 2001; Bastianetto and Quirion, 2002).

Our first objective was to make an evaluation of the real antioxidant properties of new compounds, obtained by organic synthesis. The choice of the compounds prepared was based both on the knowledge that the hydroxyl groups of the phenol ring are usually responsible for the antioxidant properties and on the knowledge that nitrogen compounds (amidines and, in particular, nitrogen heterocycles incorporating an imidazole unit), can easily interact with active centers in living organisms. The association of these two 
moieties in the same molecule was expected to lead to new structures capable of acting as antioxidants in living systems. The structures, FMA4, FMA5, FMA7 and FMA8 are nitrogen compounds and differ mainly in the presence of hydroxyl groups located in the C-3 and/or C-4 position of an aromatic substituent. Molecules incorporating conjugated systems with nitrogen atoms are also known to stabilize free radicals (Wentrup, 1984) and this combination was also expected to enhance the antioxidant activity of the phenolic unit. (Areias et al., 2001). We have submitted cells to a deleterious oxidant stimulus in order to evaluate the level of protection verified in the presence of the compounds. In addition, the compounds cytotoxicity screening was done.

Apoptosis is an active process of cell death, which occurs during several pathological situations to which oxidative stress is also associated. It can be induced by two different pathways: the death-receptor pathway (mediated by caspase-8) and the mitochondrial pathway (mediated by caspase-9). Both pathways ultimately lead to the activation of effector caspases, such as caspase-3 (Chandra et al., 2000; Zimmermann et al., 2001; Cain et al., 2002; Mathiasen and Jaattela, 2002).

Considering the lipophilic profile of our compounds we tried to elucidate the intracellular biochemical pathways in which they can be active, namely in the reversal of apoptotic phenomena. Cell apoptosis was induced by the alkaloid staurosporine and the location, in the apoptotic cascade, in which they can act, was evaluated through the effect on induced caspases activity.

Finally, taking advantage of synthesis strategies, to manipulate the new structures, we also intend to obtain an improvement of the antioxidant properties with the cyclization of 
the compounds since heterocyclic aromatic systems enhances the free radical stabilization (Wentrup, 1984).

\section{Materials and methods}

\section{Compounds}

The new compounds used in this study (Fig. 1) were prepared from the reaction of an appropriate phenolic aldehyde with a substituted amidine. The experimental procedure was adapted from previous work (Booth et al., 1999) carried out on a selection of monosubstituted aldehydes. A detailed procedure is being submitted for publication. The drugs were divided according to their chemical structure, namely the ones presenting a linear chain and the ones presenting a cyclic structure. The compounds were provided as a yellowish powder, were reconstituted in absolute ethanol, aliquoted and maintained frozen until utilization. Each aliquot was defrosted only once.

Fetal bovine serum (FBS) was from BioChrom KG (Berlin, Germany); horse serum donor herd was purchased from Gibco (Paisley, UK). 2,2-diphenyl-1-picrylhydrazyl (DPPH) and 6-hydroxi-2,5,7,8-tetrametilcromano-2-carboxylic acid 97\% (trolox) were purchased from Sigma-Aldrich Chemie (Berlin, Germany). Coomassie Blue was obtained from Fluka (Buchs, Switzerland). All other reagents, including those for cell culture, were purchased from Sigma Chemical Company (St Louis, USA). 


\section{Biological models}

Two different cell models were used: a mice fibroblast cell line, L929 (ECACC), consisting of undifferentiated and pluripotent cells, used in this study for cytotoxicity assays since they are a good model for that purpose (Fischer et al., 2003); and a neuronal cell line, PC12, established from a rat adrenal pheochromocytoma (Greene and Tischler, 1976), which is widely used as a model to study different processes that can be correlated to what occurs in pathological conditions related with oxidative stress. (Oliveira et al., 2002; Wang et al., 2003; Piga et al., 2005; Hiroi et al., 2005). Both cell lines were maintained in a humidified incubator containing $95 \%$ air and $5 \% \mathrm{CO}_{2}$.

L929 cells were routinely grown in 25 or $75 \mathrm{~cm}^{2}$ tissue culture flasks in DMEM supplemented with $10 \% \quad(\mathrm{v} / \mathrm{v})$ heat-inactivated FBS and $1 \% \quad(\mathrm{v} / \mathrm{v})$ of an antibiotic/antimycotic solution containing 10000 units of penicillin, $10 \mathrm{mg}$ streptomycin and $25 \mu \mathrm{g}$ amphotericin B per ml. For toxicity experiments, cells were trypsinized with a $0.25 \%$ trypsine/EDTA solution for 3 minutes and plated at $5 \times 10^{5}$ cells $/ \mathrm{ml}$ on 24 well plates $(0.5 \mathrm{ml} /$ well $)$ and left for adhesion during 5 hours.

PC12 cells were cultured in suspension in $75 \mathrm{~cm}^{2}$ flasks, in RPMI-1640 supplemented with $10 \%(\mathrm{v} / \mathrm{v})$ heat-inactivated horse serum, $5 \%(\mathrm{v} / \mathrm{v})$ heat-inactivated FBS and $1 \%(\mathrm{v} / \mathrm{v})$ antibiotic/antimycotic solution (as described above). Cells were passed twice a week. Before each assay the cell aggregates were carefully disrupted by pipetting and the separated cells plated in poly-D-lysine-coated multiwells, at a density of $1.6 \times 10^{5}$ cells $/ \mathrm{cm}^{2}$, and left for adhesion overnight. 
Determination of the radical scavenging effect - DPPH assay

Free radical scavenging capacity of the compounds was determined using DPPH discoloration method (Lehuédé et al., 1999). DPPH (2,2-diphenyl-1-picrylhydrazyl) is a stable radical commonly used for the determination of compounds antiradical activity. The reduction of this radical by an antioxidant compound results in a decrease in absorbance and is proportional to the number of electrons absorbed (Bondet et al., 1997), indicating the antiradical capacity of the substances in study.

A volume of $20 \mu \mathrm{l}$ of different concentrations of compound was placed in a 96-well plate and mixed with $180 \mu \mathrm{l}$ of a $0.002 \%$ ethanolic DPPH solution. The absorbance was read at $517 \mathrm{~nm}$ along the time, in a Spectra Max 340PC microplate reader, versus a control containing ethanol instead of the compound in study. The absorbance stabilization time was determined. All measurements were performed in triplicate. The inhibition of discoloration was expressed as a percentage, towards the control, and the $\mathrm{IC}_{50}$ were then obtained from the inhibition curve. Antiradical efficiency (AE) was then determined according to the formula

$$
\mathrm{AE}=1 /\left(\mathrm{IC}_{50} \times \mathrm{T}_{I C 50}\right)
$$

where $\mathrm{IC}_{50}$ is the concentration needed to reduce the DPPH discoloration by $50 \%$ and $\mathrm{T}_{\text {IC50 }}$ is the time needed to reach discoloration steady state at $\mathrm{IC}_{50}$ concentration (Sanchez-Moreno et al., 1998). 
Analysis of cell survival

Cell viability in the presence of the compounds was evaluated by the MTT reduction test and by the lactate dehydrogenase (LDH) release method.

The extent of reduction of MTT was measured spectrophotometrically at $570 \mathrm{~nm}$ according to the method of (Mosmann, 1983). Briefly, $0.5 \mathrm{ml}$ MTT (final concentration $0.5 \mathrm{mg} / \mathrm{ml}$, in Krebs medium, $\mathrm{pH}=7.4$ ), prepared just before usage and maintained in the dark, was added to the L929 cells. The plate, wrapped in aluminium foil, was left incubating for 2 hours. Hydrogen chloride $0.04 \mathrm{M}$ in isopropanol was then added, followed by 2 hours more of orbital shaking, in the dark, to dissolve the formazan crystals. The survival of L929 cells was expressed as the percentage of OD towards control cells, containing the same amount of the drug solvent, ethanol.

LDH activity was measured spectrophotometrically according to the method described by Rego and Oliveira, 1995, slightly modified. Briefly, cells were incubated in the presence of the compounds, in the same conditions as the ones used for the MTT test. A small volume of medium was collected for determination of extracellular LDH. The cells attached to the wells were then lysed to obtain the release of intracellular LDH. The enzyme activity was then assessed at room temperature on a microplate reader (Spectra Max 340PC), by following, during 3 minutes, the rate of conversion of reduced nicotinamide adenine dinucleotide $(0.28 \mathrm{mM} \mathrm{NADH}$, $)$ to oxidized nicotinamide adenine dinucleotide $\left(\mathrm{NAD}^{+}\right.$), at $340 \mathrm{~nm}$. Pyruvate $0.32 \mathrm{mM}$ (in phosphate buffer, $\mathrm{pH} 7.4$ ) was used as substrate. The LDH released to the extracellular medium was expressed as a percentage of the total LDH activity (extracellular + intracellular LDH). 
Evaluation of the degree of hydrophobicity of the drugs

The drugs hydrophobicity was determined by measuring the partition coefficients (PC) and the retardation factors (Rf).

The PC were measured in an n-octanol/HEPES system. The nitrogen compounds were dissolved in n-octanol at a concentration of $20 \mu \mathrm{M}$, and $1 \mathrm{ml}$ of each solution was shaken with $20 \mathrm{ml}$ HEPES (20 mM, pH 7.4) for about 10 minutes, at room temperature. The two different phases formed were then separated by centrifugation. After the determination of the absorbance peaks for each drug (400 nm for FMA4 and FMA7, and $410 \mathrm{~nm}$ for FMA5 and FMA8) the PC values were then calculated using the formula:

$$
\mathrm{PC}=\log \left(\mathrm{C}_{\mathrm{O}} / \mathrm{C}_{\mathrm{H}}\right)
$$

where $\mathrm{C}_{O}$ and $\mathrm{C}_{\mathrm{H}}$ are the concentrations of the drugs in n-octanol and in HEPES, respectively. The $\mathrm{C}_{\mathrm{H}}$ values were indirectly determined by calculating the difference between the initial and the final concentrations of the drug in octanol.

The Rf were determined by thin layer chromatography (TLC) on silica gel plates by using a solvent system consisting of chloroform:ethyl acetate:acetic acid in a 16:8:1 proportion. The plates were pre-run with the solvent and allowed to dry before the samples application. Once the plates dried, a volume of about $2 \mu 1$ of each drug was applied, and the samples were then allowed to run again. 
Measurement of the extent of lipid peroxidation - TBARS assay

The pair ascorbate/iron was chosen to induce membrane lipid peroxidation.

After removal of the culture medium, the cells were washed in Krebs medium, containing (in $\mathrm{mM}$ ): $140 \mathrm{NaCl}, 5 \mathrm{KCl}, 1.5 \mathrm{CaCl}_{2}, 1 \mathrm{MgCl}_{2}, 1 \mathrm{NaH}_{2} \mathrm{PO}_{4}, 5.6$ glucose, and $20 \mathrm{HEPES}$, $\mathrm{pH}$ 7.4. Incubation in the same medium, with ascorbate/ $\mathrm{Fe}^{2+}$ was performed for $60 \mathrm{~min}$, at $37^{\circ} \mathrm{C}$, at a final volume of $4 \mathrm{ml} /$ well. The drugs were pre-incubated for three hours prior to the addition of the oxidant pair.

Lipid peroxidation was evaluated by measuring Thiobarbituric Acid-Reactive Substances (TBARS). In practice, TBARS are expressed in terms of malondialdehyde (MDA) equivalents that react with thiobarbituric acid (TBA) (Hodges et al., 1999).

After the induction of lipid peroxidation, the incubation medium was removed and the reaction was stopped by placing the cells on ice, and adding $1560 \mu \mathrm{l}$ of ice-cold $15 \mathrm{mM}$ Tris, pH 7.4 to each well. The cells were then scrapped and a pool of two wells content, in the same experimental conditions, was made into a glass assay tube. An aliquot of each sample was taken for posterior protein determination. To each tube containing $3 \mathrm{ml}$ of the cell suspension, $6 \mathrm{ml}$ of a TBA-TCA-HCl-BHT reagent, containing $0.375 \% \mathrm{TBA}(\mathrm{w} / \mathrm{v})$, $37.5 \%$ trichloroacetic acid (TCA), $0.25 \mathrm{~N} \mathrm{HCl}$, and $6.8 \mathrm{mM}$ butylated hydroxitoluene (BHT), were added. Samples were boiled for 15 minutes, removed to ice for rapid cooling and centrifuged at $3000 \mathrm{rpm}$ for $15 \mathrm{~min}$ in a bench Heraeus labofuge. The supernatants were collected, and the absorbance was read, at $530 \mathrm{~nm}$ (Minotti and Aust, 1987), in a Perkin-Elmer UV/Vis Spectrometer. The amount of TBARS produced was calculated, using a molar absorption coefficient of $1.56 \times 10^{5} \mathrm{M}^{-1} \mathrm{~cm}^{-1}$, corrected for the 
total protein content (Sedmak and Grossberg, 1977) and expressed as nmol TBARS/mg protein.

The antioxidant capacity of the drugs was evaluated determining the percentage of protection, offered by each drug against the lipid peroxidation induced by the oxidant pair, by using the normalization proposed by (Singh et al., 1998):

$$
\% \text { Protection }=1-[(\mathrm{D}-\mathrm{C}) / \mathrm{OP}] \times 100
$$

where $\mathrm{D}$ is the amount of TBARS in the presence of the drug, $\mathrm{C}$ is the basal lipid peroxidation (negative control) and OP is the amount of TBARS in the presence of the oxidant pair.

\section{Determination of caspase activity}

The activity of caspases 3,8 and 9 was assessed by determining the cleavage of the respective colorimetric substrate. The method used was adapted from the one described by (Cregan et al., 1999). After 1 or $2 \mu \mathrm{M}$ STS treatment for 5 hours, the culture medium was removed and the cells were rinsed twice with PBS and extracted on ice with a lysis buffer (1 mM Na-EDTA, 1 mM Na-EGTA, 2 mM MgCl $2.6 \mathrm{H}_{2} \mathrm{O}, 25$ mM HEPES, pH 7.5 supplemented with $100 \mu \mathrm{M}$ PMSF and $2 \mathrm{mM}$ DTT). The cell extracts, sonicated for 10 seconds, were centrifuged at $14000 \mathrm{rpm}$ (Sigma $2 \mathrm{~K} 15$ centrifuge) for $10 \mathrm{~min}$, at $4^{\circ} \mathrm{C}$. The supernatants were removed and assayed for protein content. Aliquots containing $50 \mu \mathrm{g}$ of protein were then added to a reaction buffer (10\% sucrose, $0.1 \%$ CHAPS, $25 \mathrm{mM}$ 
HEPES, pH 7.4) supplemented with 10 mM DTT. The reactions (in a final volume of 500 $\mu \mathrm{l})$ were initiated after addition of the following colorimetric substrates $(100 \mu \mathrm{M})$ : AcDEVD-pNA, for caspase-3-like protease activity, Ac-IETD-pNA, for caspase-8-like protease activity, or Ac-LEHD-pNA, for caspase-9-like protease activity. After $2 \mathrm{~h}$ incubation in the dark, at $37^{\circ} \mathrm{C}, 200 \mu$ of the reaction were transferred to a 96 -well plate and the substrates cleavage was measured at $405 \mathrm{~nm}$. Caspases activity, expressed in nmol substrate cleaved/ mg protein, was then expressed as the increase of OD above the control (cells incubated in the absence of STS).

Hoechst 33342 and propidium iodide cell staining

Apoptosis and necrosis were distinguished using combined staining of the chromatin dye Hoechst 33342 and propidium iodide (PI). In brief, $100 \mu \mathrm{l}$ of PI at $4 \mu \mathrm{g} / \mathrm{ml}$ were added to cells adhered to coverslides for $5 \mathrm{~min}$. After fixation of the cells with paraformaldehyde $4 \%, 400 \mu \mathrm{l}$ of Hoechst at $5 \mu \mathrm{g} / \mathrm{ml}$ were added for $10 \mathrm{~min}$. The nuclei were then observed by fluorescence microscopy and counted according to nucleus morphology and label. The percentages of viable, apoptotic and non-viable cells were determined by counting at least 300 cells by experiment. 


\section{Statistical analysis}

Data are expressed as the mean \pm S.E.M., of the indicated number of experiments. The significance of the differences between the means observed was evaluated using the unpaired two-tailed Student's t-test. A difference of $p \leq 0.05$ was considered significant.

\section{Results}

Determination of the radical scavenging effect - DPPH assay

It is well established that the antioxidant activity of a drug depends on its ability to scavenge free radicals (Beckman and Ames, 1998; Behl and Moosmann, 2002). In order to evaluate the radical scavenging activity of the compounds by themselves, we used the DPPH discoloration method, which is routinely used, as a first approach (Okawa et al., 2001; Molyneux, 2004).

The first step was to determine the stabilization time for the discoloration of a DPPH ethanolic solution. We considered 40 minutes as a relative steady state discoloration time for all the compounds. With the absorbance results obtained at this time point we calculated the percentages of inhibition of discoloration for each drug concentration. The resulting dose-response curves, from which we determined the $\mathrm{IC}_{50}$ values are represented in Fig. 2. For the antiradical efficiency calculations we considered two parameters: the $\mathrm{IC}_{50}$ obtained for each drug (directly taken from Fig. 2) and the time required by each compound to reach the steady state of DPPH discoloration, at this $\mathrm{IC}_{50}$ 
concentration. This time of stabilization at the $\mathrm{IC}_{50}$ concentration was found to be 20 minutes for FMA5, FMA8 and trolox, and 40 minutes for FMA4, FMA7 and $\alpha$ tocopherol.

The results in Table 1 show that FMA5 and FMA8 have the highest antiradical efficiency values, even higher than that obtained for the traditional antioxidants, trolox and $\alpha$ tocopherol. FMA4 and FMA7 present lower antiradical efficiency values and therefore lower antiradical activity.

Effect of the compounds on cells survival

The $\mathrm{IC}_{50}$ values determined above were used for the evaluation of the new compounds cytotoxicity. Considering the eventual metabolization of the compounds in vivo, we tested them in a concentration five-fold the $\mathrm{IC}_{50}$. Cellular viability was determined in L929 fibroblasts used as a model for cell toxicity evaluation (Fischer et al., 2003; Masoud et al., 2003). Two different methods were used: the MTT reduction test, which reflects the reducing capacity of the cells and the LDH release test, which is related to the plasma membrane integrity.

Results presented on Fig. 3 show that none of the compounds affects the cells ability to reduce MTT, indicating that the enzymatic machinery involved in the metabolic oxireduction processes was not affected by the compounds concentrations tested. In addition, none of the compounds led to an increase in the extracellular enzyme lactate dehydrogenase, which is indicative of the integrity of the cells plasma membrane. The 
results of both tests are in accordance, since no statistical differences were observed between the bars representing both assays, with the same compound In this way, we can say that the new compounds are not toxic even for a concentration five-fold greater than the $\mathrm{IC}_{50}$ determined by the $\mathrm{DPPH}$ discoloration method.

\section{Analysis of the degree of compounds hydrophobicity}

To evaluate if the antioxidant activity of the compounds could be related to their capacity to enter the lipid bilayer, we determined the degree of hydrophobicity of each drug. Table 2 shows the partition coefficient values for all the drugs tested using an n-octanol/HEPES system as well as the retardation factors in a TLC system.

According to the results, FMA4 shows a higher affinity for the octanol phase than all the other drugs (highest PC value) and a less affinity for the silica plate (highest Rf value). Furthermore, all the other compounds (FMA5, FMA7 and FMA8) present PC values and Rf values higher than the hydrosoluble form of vitamin E, trolox. Taken together, these results indicate the following order on the ability to cross the lipid bilayer: FMA4 $>$ FMA7 $>$ FMA5 $>$ FMA8, which correlates well with their molecular structure, that is, the compounds with only one hydroxyl group have a greater ability to cross the lipid bilayer.

\section{Effect of the compounds on ascorbate/Fe ${ }^{2+}$-induced lipid peroxidation}

Membrane lipid peroxidation can be induced in biological systems by several agents, like ascorbate/ $\mathrm{Fe}^{2+}, \mathrm{ADP} / \mathrm{Fe}^{2+}$ or $\mathrm{H}_{2} \mathrm{O}_{2} / \mathrm{Fe}^{2+}$ (Markesbery, 1997; Rego et al., 1998; Santos and Moreno, 2001). We chose the oxidant pair ascorbate $/ \mathrm{Fe}^{2+}$ which is currently 
described as adequate in similar approaches (Katayama et al., 1989; Rego et al., 1998; Areias et al., 2001).

Ascorbate acts as a pro-oxidant agent, reducing $\mathrm{Fe}^{3+}$ and originating $\mathrm{Fe}^{2+}$. This $\mathrm{Fe}^{2+}$ originates hydroxyl radicals by the Fenton reaction (Halliwell and Gutteridge, 1999; Shapiro and Saliou, 2001; Hiroi et al., 2005) susceptible of inducing the oxidative stress events cascade.

The evaluation of the best pair to induce lipid peroxidation was still done using the L929 cell line. Results in the insert of Fig. 4 clearly show that, among the different oxidant pairs tested, $2 \mathrm{mM}$ ascorbate / $400 \mu \mathrm{M} \mathrm{Fe}^{2+}$, was the one that resulted in higher lipid peroxidation levels. However no statistical differences were found between the different conditions tested and the control. On the other hand, the PC12 cell line, currently used in this type of studies (Kruman et al., 1998; Pereira et al., 1999) seems to be an adequate model, showing a lipid peroxidation increase of 7.43 times relatively to the control with the pair $2 \mathrm{mM}$ ascorbate / $100 \mu \mathrm{M}$ iron (Fig. 4).

Results in Fig. 5 show the oxidation protection induced by the compounds in study. Because the negative and positive control (cells only, and cells with the oxidant pair) have different values from experience to experience we decided to calculate the relative drug protection of lipid peroxidation using the normalisation proposed by Singh et al., 1998 (see Materials and Methods).

In the presence of the oxidant pair $2 \mathrm{mM}$ ascorbate / $100 \mu \mathrm{M}$ iron, pre-incubation with the drugs FMA4, FMA5 and FMA7 showed protection on lipid peroxidation, which was similar or slightly superior to trolox but inferior to $\alpha$-tocopherol, which were used as means of comparison. No significant differences were observed between two different 
concentrations of the same compound, except for the cases of $\alpha$-tocopherol and FMA8. This compound was indeed the drug presenting the highest protective effect on lipid peroxidation, namely for a concentration two-fold the $\mathrm{IC}_{50}(69.80 \pm 10.95 \%)$. This fact, together with its reduced ability to cross the lipid bilayer (Table 2), suggest an action, for FMA8, restricted to the membrane surface.

We can say that the new compounds show a very good capacity to revert the damage caused by the oxidant pair to membrane lipids and that this capacity correlates well with their molecular structures.

Evaluation of the compounds protective effect on apoptotic pathways

As the new compounds in study revealed to be promising in which respects to their antioxidant activity we went further on trying to elucidate their potential as protectors of apoptotic phenomena. It is well known that caspase-3 has a primordial role in triggering the cascade of events leading to apoptosis, participating in the cleavage or degradation of various important substrates and eventually in the activation of other caspases (Zimmermann et al., 2001). Staurosporine (STS) is an alkaloid isolated from Streptomyces sp., which seems to activate common mechanisms of cellular death in all cells. For this reason it is commonly used as an apoptotic inducer (Kruman et al., 1998) although the exact pathways of its action are not yet completely clarified.

Caspase-3 activity was induced in PC12 cells, in the conditions optimized by Oliveira et al., 2003. In this assay we tested only FMA4, FMA7 and FMA8. The relative low liposolubility of FMA5 together with its inability to protect membrane lipid peroxidation 
(Table 2 and Fig. 5) suggested that its action at the level of caspase- 3 activation would not be of great relevance. In the presence of the compounds tested we observed a reduction of caspase-3 activity induced by $1 \mu \mathrm{M}$ STS only for FMA4 and FMA7 (Fig. 6A). In the case of FMA4 this reduction was statistically significant for the lowest concentration tested $(19.8 \mu \mathrm{M})$. For both FMA4 and FMA7, the decrease in enzyme activity is slightly higher than that observed for $\alpha$-tocopherol, which indicates a higher ability of these compounds to protect the intracellular pathways that trigger apoptosis. FMA8 is the least effective of the new drugs tested, presenting a protective effect similar to the one induced by $\alpha$-tocopherol although none of them shows a significant protective effect. For all cases, there are no differences between the two concentrations tested.

The compounds protective effect observed requires a pre-incubation period with the drugs, not being observed when the incubation with the drugs and STS was simultaneous (Fig. 6B). This fact and the lower protective effect of FMA8 on the intracellular pathways related to apoptosis can both be explained by its lower liposolubility.

Caspase- 3 is an effector caspase that can be proteolytically activated either by the death receptor pathway (caspase-8) or by the mitochondrial pathway (caspase-9). Since the new compounds are able to reduce the caspase- 3 activity, it becomes important to know by which pathway that reduction is achieved, that is, in which apoptotic pathway the compounds exert a greater protection.

Results on Fig. 7 show that the initiator enzymes activities increased $1.93 \pm 0.21, p \leq 0.05$ times (caspase-8) and $1.90 \pm 0.23, p \leq 0.05$ times (caspase-9) in the presence of STS. The effect of all of the compounds tested (FMA4, FMA7 and FMA8) is indicative of their protective action on both apoptotic pathways, since they lead to a decrease of both 
caspase- 8 and caspase- 9 activities. However, the reduction observed in the presence of the compounds is not as high as the one evidenced by $\alpha$-tocopherol, namely for the caspase- 8 activity, in which the colorimetric substrate cleavage is decreased to the basal level.

The slight protection observed in both caspases ( 8 and 9) is of the same order of magnitude, indicating that there is not a preferential pathway leading to the observed decrease of caspase-3 activity.

The ability of the new compounds to protect cells from the deleterious effects induced by STS was also analysed by fluorescence microscopy. Cells were incubated for the same time period and at the same concentration of STS used to assess caspase-3 activity protection.

Hoechst 33342 freely enters living cells and therefore stains the nuclei of viable cells, as well as those that died by apoptosis or necrosis. Apoptotic cells can be distinguished from viable and necrotic cells on the basis of nuclear condensation and fragmentation. On the other hand, PI only enters in cells with damaged cell membranes. So, viable cells are PI negative while necrotic cells are PI positive.

After exposition of the cells to $1 \mu \mathrm{M}$ STS (Fig. 7) we observed a mean of $17.0 \pm 2.5 \%$ of apoptotic cells and $11.7 \pm 2.5 \%$ of necrotic cells. However, pre-incubation of the cells with FMA7 at a concentration equal to the $\mathrm{IC}_{50}$ was responsible for the reduction of apoptotic cells to $14.3 \pm 1.2 \%$ and necrotic ones to $4.7 \pm 0.7 \%$. No statistically significant differences were observed for a concentration two-fold the $\mathrm{IC}_{50}$, since it reduced the number of apoptotic cells to $12.0 \pm 1.7 \%$ and of necrotic cells to $5.3 \pm 0.9 \%$. In cells used as a control, the percentage of apoptotic and necrotic cells was less than $2 \%$. With this 
technique we are observing damages to the nuclei of the cells, which occurs later on the apoptotic cascade. This fact can explain, in part, the discrepancy on cell protection obtained by fluorescence microscopy and the one obtained with the caspases activity assays. Nevertheless, the results altogether clearly indicate compounds protection on cell death phenomena, including necrotic cell death.

\section{Cyclic compounds}

The cyclization of the new structures was expected to generate compounds with higher antioxidant activity. We tested FMA698 and FMA699 (Fig. 10), the cyclic forms of FMA4 and FMA7, respectively, and an increase in antioxidant activity was expected, as a heterocyclic aromatic system usually enhances the free radical stabilization. Nevertheless, results on Fig. 10 show that the incubation of the cells with the cyclic compounds in the presence of the oxidant pair (Fig. 10B) leads to an increase in TBARS levels, instead of decreasing them, which is indicative of a pro-oxidant effect. Furthermore, TBARS levels are increased even when the cells were incubated in the presence of the cyclic compounds alone (Fig. 10A). For a $200 \mu \mathrm{M}$ concentration, peroxidation levels were raised to approximately half of the levels induced by the oxidant pair ascorbate-iron. These results suggest that the cyclic compounds, per si, are capable of removing hydrogen atoms directly from membrane lipids, thus acting as pro-oxidants. However, the mechanism involved is probably different, because the peroxidation in the presence of ascorbate occurs by an indirect way: first of all ascorbate reduces iron and then free radicals are formed (Shapiro and Saliou, 2001). 
The absence of antioxidant activity in these cyclic compounds was confirmed by the DPPH discoloration method, as the cyclic compounds were unable to reduce the DPPH radical up to a concentration of $500 \mu \mathrm{M}$ (data not shown).

\section{Discussion}

The activity of a compound as antioxidant is dependent on its capacity to "scavenge" free radicals.

DPPH discoloration test provides the primary antioxidant activity of a compound, that is, its ability to directly scavenge free radicals. The substituents present in the molecule, and particularly their positions, contribute to the differences seen between compounds (Yokozawa et al., 1998; Lebeau et al., 2000). Previous studies with flavonoids are indicative that the presence of two hydroxyl groups in the $\mathrm{C} 3$ and $\mathrm{C} 4$ positions of their structures is responsible for an increase in the capacity to reduce the DPPH radical (Yokozawa et al., 1998; Okawa et al., 2001). So, looking to the molecular structures in study (Fig. 1), a higher antiradical activity is expected for the compounds FMA5 and FMA8. In fact, results in Table 1 confirm that they are the ones with lower $\mathrm{IC}_{50}$ values and higher antiradical efficiency, even superior to the two forms of vitamin E tested. On the other hand, FMA4 and FMA7, which only have one hydroxyl group in the C3 position of the aromatic ring, presented higher $\mathrm{IC}_{50}$ values and also a lower antiradical efficiency.

When evaluating a compound with therapeutical potential the screening of toxicity has a special relevance. The results of the two tests employed (MTT reduction and LDH 
release) were in accordance with each other and both showed that the compounds in study were not toxic even for a concentration five-fold greater than the $\mathrm{IC}_{50}$ determined by the DPPH discoloration method. This high concentration tested provides us a safety margin to conclude about the lack of cytotoxicity of these new compounds, even if we consider no complete metabolization and/or elimination in vivo and a consequent accumulation, after repeated doses, in blood circulation.

The general antioxidant activity of a compound can be related with different factors, including its capacity to interact and/or cross the lipid bilayer. On the other hand, the incorporation of a compound in a lipid bilayer is affected by several factors, namely electrostatic interactions, hydrogen bond formation with the polar groups of phospholipids, hydrophobic interactions between the fatty acid chains and also by the molecular geometry of both phospholipids and compounds (Saija et al., 1995).

As it can be observed (Table 2), the new compounds in study all have a lipophilic profile, which is very similar to some common natural compounds with antioxidant activity (Areias et al., 2001). Their ability to cross the biological membranes varies in the same order, independently of the system used to evaluate their lipophilicity. In this way, FMA4 is the one with higher ability to establish hydrophobic interactions with n-octanol (higher PC value). On the other hand, it presents a lower ability to establish hydrogen bonds with silica (higher Rf value). Altogether, we can say that FMA4 is the one that more easily crosses the lipid bilayer, followed by FMA7, FMA5 and FMA8.

Looking at the chemical structures of the compounds (Fig. 1), the higher liposolubility of FMA4 and FMA7 may be related to the presence of only one hydroxyl group in the C3 position of the aromatic ring. FMA5 and FMA8, which have two hydroxyl groups, in C3 
and $\mathrm{C} 4$ positions, are less liposoluble. The presence of more hydroxyl groups in a molecule may, on one hand, increase its antiradical activity but, on the other hand, may originate more hydrophilic molecules with less ability to cross the lipid bilayer and act at the intracellular level providing, for example, lower protection on lipid peroxidation.

The evaluation of the protective effect of the compounds on lipid peroxidation is a way to analyse the compounds secondary antioxidant activity, since it gives their ability to quelate the metallic ion used $\left(\mathrm{Fe}^{2+}\right)$ to induce peroxidation through Fenton reactions with free radicals. This fact prevents iron from peroxidating the membrane.

Results in Fig. 5 show a protection of about $45 \%$ for the FMA4 and FMA7 compounds, with no statistically difference between the two concentrations tested. However, the protection induced by FMA8 is different for the two concentrations tested, and for a concentration twice the $\mathrm{IC}_{50}$, their effect is comparable to that induced by $\alpha$-tocopherol. FMA5 presented low protection values on lipid peroxidation and was the only compound (apart from trolox) which revealed to be statistically different from $\alpha$-tocopherol, which is indicative of its inability to act at the intracellular level.

Since lipid peroxidation occurs mainly due to the free radicals formed intracellularly (Spiteller, 2001), the higher the ability of the compounds to cross the lipid bilayer, the higher will be their capacity to prevent those radicals from inducing the peroxidation of membrane lipids. Effectively, the protection profile of FMA4 and FMA7 does not correlate with the antiradical efficiency shown in Table 1. This apparent discrepancy can be explained by the compounds liposolubility profile, given by their partition coefficients (Table 2). As previously discussed, although the presence of less hydroxyl groups in these two compounds confers them a lower antiradical efficiency, it also may turn them 
into more lipophilic compounds, which can explain its higher protective effect on lipid peroxidation. Taking as comparison the antioxidant activity of trolox and its liposoluble form $\alpha$-tocopherol we can conclude that FMA4 and FMA7, which have an intermediate liposolubility, really present an intermediate protection profile. FMA8 presented a high protection on lipid peroxidation, which could be expected from its high antiradical efficiency, but not from its liposolubility profile (as it is shown in Table 2, FMA8 is more hydrophobic). The results obtained with this compound suggest an action more restricted to the membrane surface. Piga et al., 2005 suggested a similar effect for extracellular GSH, which is hardly incorporated in the membranes.

Apoptosis is an active process of cell death, which occurs during several pathological situations to which oxidative stress is also associated (Kruman et al., 1998; Chandra et al., 2000; Ray et al., 2000; Reed, 2001; Jang et al., 2004). Among the different events that characterize apoptosis such as the decreasing of cellular volume, the chromatin condensation and the formation of apoptotic bodies, there is the activation of cytoplasmic caspases which are, by their turn, responsible for the activation of other intracellular proteins (Chandra et al., 2000). It is well described the relationship between the activation of caspase-3 and the execution of apoptotic cascade in pathologies such as Alzheimer's (Jang et al., 2004), Parkinson's disease (Viswanath et al., 2001) or cerebral ischemia (Chen et al., 1998). Moreover, previous studies (Kruman et al., 1998; Krohn et al., 1998), using PC12 cell line as a biological model, have shown that STS induces intracellular ROS accumulation. It is also known that staurosporine easily permeates the plasma membrane, acting inside cells as a potent inhibitor of protein kinase $\mathrm{C}$ and other kinases (Ruegg and Burgess, 1989), initiating, by this way, the intracellular cascade leading to 
cell death. However the intracellular pathways that can be modulated by STS are not yet completely clarified (Gil et al., 2003) and a recent report indicates that some necrosis can also occur, in addition to the expected apoptosis (Chen et al., 2005).

We obtained a significant increase in caspase-3 activity with $1 \mu \mathrm{M}$ staurosporine which was reverted when cells were pre-incubated with the new compounds in study (Fig. 6). Besides the compounds lipophilic profile, pre-incubation is required in order to assure their permeation and a posterior effectiveness in reverting the deleterious effect of the apoptotic stimulus inside the cells. On the other hand the slight protection observed for caspase- 8 and caspase-9 activation (Fig. 7) are indicative that the compounds do not have a preferential pathway for acting and are also indicative that the cumulative effect on the decrease of caspases 8 and 9 results in the clear effect on the effector caspase, caspase- 3 . However, the decrease observed in caspase- 3 activity can have the contribution of other mechanisms triggered, for example, by a raise in intracellular calcium, also susceptible to be induced by staurosporine (Kruman et al., 1998). We intend to further investigate the role of the new drugs on these mechanisms. Another interesting result was the necrosis protection effect observed in Fig. 9, with FMA7. This protection profile could be a benefit for these new drugs, which also need further clarification.

One of the main features of the new compounds in study is the possibility to manipulate their structures, in order to optimize their potential, namely as antioxidants. The cyclization of the spacer in the linear structures was expected to increase the protection from oxidative stress. However the results obtained with the cyclic forms of FMA4 and FMA7 (FMA698 and FMA699) indicate a pro-oxidant behaviour since an increase in TBARS levels is observed, even in the absence of the oxidant pair (Fig. 10A and B). This 
pro-oxidant behaviour was corroborated by the absence of antiradical activity, until a 500 $\mu \mathrm{M}$ concentration, evaluated by the DPPH discoloration method. We can conclude that our cyclic structures have a slight pro-oxidant effect so another therapeutical potential needs to be further investigated.

\section{Acknowledgments}

We wish to thank Prof. A. J. Moreno and Prof. Catarina Oliveira for the fruitful discussions.

This work was partially supported by Foundation for Science and Technology (FCT, Portugal), through the POCTI and/or FEDER programmes.

J. P. Silva is a recipient of a grant from the Foundation for Science and Technology (SFRH/BD/17174/2004). F. M. Areias is also a recipient of a grant from the Foundation for Science and Technology (SFRH/BD/3185/2000). 


\section{References}

Areias F.M., Rego C., Oliveira C., Seabra R.M., 2001. Antioxidant effect of flavonoids after ascorbate $/ \mathrm{Fe}^{2+}$-induced oxidative stress in cultured retinal cells. Biochemical Pharmacoloy 62, 111118.

Bastianetto S., Quirion R., 2002. Natural extracts as possible protective agents of brain aging. Neurobiology of Aging 5687, 1-7.

Beckman K.B., Ames B.N., 1998. The free radical theory of aging matures. Physiological Reviews 78(2), $547-581$.

Behl C., 1999. Alzheimer's disease and oxidative stress: implications for novel therapeutic approaches. Progress in Neurobiology 57(3), 301-323.

Behl C., Moosmann B., 2002. Antioxidant neuroprotection in Alzheimer's disease as preventive and therapeutic approach. Free Radical Biology and Medicine 33(2), 182-191.

Bondet V., Brand-Williams W., Berset C., 1997. Kinetics and mechanisms of antioxidant activity using the DPPH free radical method. Lebbensmittel Wissenschaft Und Technologie 30, 609-615.

Bonnefont A.B., Munoz F.J., Inestrosa N.C., 1998. Estrogen protects neuronal cells from the cytotoxicity induced by acetylcholinesterase-amyloid Complexes. FEBS Letters 441(2), 220-224.

Booth B.L., Costa F.A.T., Mahmood Z., Pritchard R.G., Proença M.F., 1999. Synthesis of (Z)-N-(2-amino1,2-dicyanovinyl)formamide O-alkyloximes and a study of their cyclization in the presence of base. Journal of the Chemical Society-Perkin Transactions 1(13), 1853-1858.

Cain K., Bratton S.B., Cohen G.M., 2002. The Apaf-1 apoptosome: a large caspase-activating complex. Biochimie 84(2-3), 203-214.

Chandra J., Samali A., Orrenius S., 2000. Triggering and modulation of apoptosis by oxidative stress. Free Radical Biology and Medicine 29(3-4), 323-333.

Chen G.G., Sin, F.L., Leung B.C, Ng, H.K., Poon, W.S., 2005. Differential role of hydrogen peroxide and staurosporine in induction of cell death in glioblastoma cells lacking DNA-dependent protein kinases. Apoptosis 10(1), 185-192. 
Chen J., Nagayama T., Jin K., Stetler R.A., Zhu R.L., Graham S.H., Simon R.P., 1998. Induction of caspase-3-like protease may mediate delayed neuronal death in the hippocampus after transient cerebral ischemia. The Journal of Neuroscience 18(13), 4914-4928.

Cregan S.P., MacLaurin J.G., Craig C.G., Robertson G.S., Nicholson D.W., Park D.S., Slack R.S., 1999. Bax-dependent caspase-3 activation is a key determinant in P53-induced apoptosis in neurons. The Journal of Neuroscience 19(18), 7860-7869.

du Toit R., Volsteedt Y., Apostolides Z., 2001. Comparison of the antioxidant content of fruits, vegetables and teas measured as vitamin C equivalents. Toxicology 166(1-2), 63-69.

Fischer D., Li Y., Ahlemeyer B., Krieglstein J., Kissel T., 2003. In vitro cytotoxicity Testing of polycations: influence of polymer structure on cell viability and hemolysis. Biomaterials 24, 11211131.

German J.B., Walzem R., 2000. The health benefits of wine. Annual Reviews on Nutrition 20, 561-593.

Gil, J., Almeida, S., Oliveira, C.R., Rego, A.C., 2003. Cytosolic and mitochondrial ROS in staurosporineinduced retinal cell apoptosis. Free Radical Biology and Medicine 35(11), 1500-1514.

Greene L.A., Tischler A.S., 1976. Establishment of a noradrenergic clonal line of rat adrenal pheochromocytoma cells which respond to nerve growth factor. Proceedings of the National Academy of Sciences U. S. A. 73(7), 2424-2428.

Halliwell, B. e Gutteridge, J. M. C., 1999. Free Radicals in Biology and Medicine, third ed. Oxford University Press, New York

Hiroi M., Ogihara T., Hirano K., Hasegawa M., Morinobu T., Tamai H., Niki E., 2005. Regulation of Apoptosis by glutathione redox state in PC12 cells exposed simultaneously to iron and ascorbic acid. Free Radical Biology and Medicine 38(8), 1057-1072.

Hodges D.M., DeLong J.M., Forney C.F., Prange R.K., 1999. Improving the Thiobarbituric Acid-ReactiveSubstances Assay for Estimating Lipid Peroxidation in Plant Tissues Containing Anthocyanin and Other Interfering Compounds. PLANTA 207(4), 604-611.

Jang J.H., Aruoma O.I., Jen L.S., Chung H.Y., Surh Y.J., 2004. Ergothioneine rescues PC12 cells from beta-amyloid-induced apoptotic death. Free Radical Biology and Medicine 36(3), 288-299. 
Jang J.H., Surh Y.J., 2001. Protective effects of resveratrol on hydrogen peroxide-induced apoptosis in rat pheochromocytoma (PC12) cells. Mutation Research 496, 181-190.

Katayama H., Demitsu T., Yaoita H., 1989. Biological and biochemical responses of skin fibroblast to oxidative stress induced by $\mathrm{Fe}^{3+}$-ascorbate. Dermatologica 179(1), 142.

Krohn, A. J., Preis, E. e Prehn, J. H., 1998. Staurosporine-induced apoptosis of cultured rat hippocampal neurons involves caspase-1-like proteases as upstream initiators and increased production of superoxide as a main downstream effector. Journal of Neuroscience 18(20), 8186-8197.

Kruman I., Guo Q., Mattson M.P., 1998. Calcium and ractive oxygen species mediate staurosporineinduced mitochondrial dysfunction and apoptosis in PC12 cells. Journal of Neuroscience Research 51(3), 293-308.

Lebeau J., Furman C., Bernier J.L., Duriez P., Teissier E., Cotelle N., 2000. Antioxidant properties of ditert-butylhydroxylated flavonoids. Free Radical Biology and Medicine 29(9), 900-912.

Lehuédé J., Fauconneau B., Barrier L., Ourakow M., Piriou A., Vierfond J.-M., 1999. Synthesis and antioxidant activity of new tetraarylpyrroles. European Journal of Medicinal Chemistry 34, 991-996.

Lovell M.A., Ehmann W.D., Butler S.M., Markesbery W.R., 1995. Elevated thiobarbituric acid-reactive substances and antioxidant enzyme activity in the brain in Alzheimer's disease. Neurology 45(8), 1594-1601.

Markesbery W.R., 1997. Oxidative stress hypothesis in Alzheimer's disease. Free Radical Biology and Medicine 23(1), 134-147.

Masoud L., Vijayasarathy C., Fernandez-Cabezudo M., Petroianu G., Saleh A.M., 2003. Effect of malathion on apoptosis of murine L929 fibroblasts: a possible mechanism for toxicity in low dose exposure. Toxicology 185(1-2), 89-102.

Mathiasen I.S., Jaattela M., 2002. Triggering caspase-independent cell death to combat cancer. Trends in Molecular Medicine 8(5), 212-220.

Minotti G., Aust S.D., 1987. The requirement for iron (III) in the initiation of lipid peroxidation by iron (II) and hydrogen peroxide. Journal of Biological Chemistry 262(3), 1098-1104. 
Miranda S., Opazo C., Larrondo L.F., Munoz F.J., Ruiz F., Leighton F., Inestrosa N.C., 2000. The role of oxidative stress in the toxicity induced by amyloid beta-peptide in Alzheimer's disease. Progress in Neurobiology 62(6), 633-648.

Molyneux P., 2004. The use of the stable free radical diphenylpicrylhydrazyl (DPPH) for estimating antioxidant activity. Songklanakarin Journal of Science and Technology 26(2), 211-219.

Mosmann T., 1983. Rapid colorimetric assay for cellular growth and survival: application to proliferation and cytotoxicity assays. Journal of Immunological Methods 65(1-2), 55-63.

Nenadis N., Zafiropoulou I., Tsimidou M., 2003. Commonly used food antioxidants: a comparative study in dispersed systems. Food Chemistry 82, 403-407.

Nordberg J., Arner E.S., 2001. Reactive oxygen species, antioxidants, and the mammalian thioredoxin system. Free Radical Biology and Medicine 31(11), 1287-1312.

Okawa M., Kinjo J., Nohara T., Ono M., 2001. DPPH (1,1-Diphenyl-2-Picrylhydrazyl) radical scavenging activity of flavonoids obtained from some medicinal plants. Biological and Pharmaceutical Bulletin 24(10), 1202-1205.

Oliveira M.T., Rego A.C., Macedo T.R., Oliveira C.R., 2003. Drugs of abuse induce apoptotic features in PC12 cells. Annual New York Academy of Sciences 1010, 667-670.

Oliveira M.T., Rego A.C., Morgadinho M.T., Macedo T.R., Oliveira C.R., 2002. Toxic effects of opioid and stimulant drugs on undifferentiated PC12 cells. Annual New York Academy of Sciences 965, 487-496.

Pereira C., Santos M.S., Oliveira C., 1999. Involvement of oxidative stress on the impairment of energy metabolism induced by $\mathrm{A} \beta$ peptides on PC12 cells: protection by antioxidants. Neurobiology of Disease 6, 209-219.

Pereira C.M., Oliveira C.R., 1997. Glutamate toxicity on a PC12 cell line involves glutathione (GSH) depletion and oxidative stress. Free Radical Biology and Medicine 23(4), 637-647.

Piga R., Saito Y., Chen Z., Yoshida Y., Niki E., 2005. Characterization of monochloramine toxicity on PC12 cells and protective Eeffect of tocopherol via antioxidative function. Archives of Biochemistry and Biophysics 436(1), 101-109. 
Ray S.K., Fidan M., Nowak M.W., Wilford G.G., Hogan E.L., Banik N.L., 2000. Oxidative stress and Ca ${ }^{2+}$ influx upregulate calpain and induce apoptosis in PC12 cells. Brain Research 852(2), 326-334.

Reed J.C., 2001. Apoptosis-regulating proteins astargets for drug discovery. Trends in Molecular Medicine $7(7), 314-319$.

Rego A.C., Santos M.S., Proença M.T., Oliveira C.R., 1998. Influence of vitamin E succinate on retinal cell Survival. Toxicology 128(2), 113-124.

Ruegg U.T., Burgess G.M., 1989. Staurosporine, K-252 and UCN-01: potent but nonspecific inhibitors of protein kinases. Trends in Pharmacological Sciences 10(6), 218-220.

Saija A., Scalese M., Lanza M., Marzullo D., Bonina F., Castelli F., 1995. Flavonoids as antioxidant agents: importance of their interaction with biomembranes . Free Radical Biology and Medicine 19(4), 481-486.

Sanchez-Moreno C., Larrauri J.A., Saura-Calixto F., 1998. A procedure to measure the antiradical efficiency of polyphenols. Journal of Science Food Agriculture 76, 270-276.

Santos D.J., Moreno A.J., 2001. Inhibition of heart mitochondrial lipid peroxidation by non-toxic concentrations of carvedilol and its analog BM-910228. Biochemical Pharmacology 61(2), 155-164.

Schroeter H., Williams R.J., Matin R., Iversen L., Rice-Evans C.A., 2000. Phenolic antioxidants attenuate neuronal cell death following uptake of oxidized low-density lipoprotein. Free Radical Biology and Medicine 29(12), 1222-1233.

Sedmak J.J., Grossberg S.E., 1977. A rapid, sensitive, and versatile assay for protein using Coomassie Brilliant Blue G250. Analytical Biochemistry 79(1-2), 544-552.

Shapiro S.S., Saliou C., 2001. Role of vitamins in skin care. Nutrition 17(10), 839-844.

Singh B., Saxena A.K., Chandan B.K., Anand K.K., Suri O.P., Suri K.A., Sattti N.K., 1998. Hepatoprotective activity of verbenalin on experimental liver damage in rodents. Fitoterapia LXIX, 135-140.

Spiteller G., 2001. Lipid peroxidation in aging and age-dependent diseases. Experimental Gerontology 36(9), 1425-1457.

Viswanath V., Wu Y., Boonplueang R., Chen S., Stevenson F.F., Yantiri F., Yang L., Beal M.F., Andersen J.K., 2001. Caspase-9 activation results in downstream caspase-8 activation and Bid cleavage in 1- 
methyl-4-phenyl-1,2,3,6-tetrahydropyridine-induced Parkinson's disease. Journal of Neuroscience 21(24), 9519-9528.

Wang L., Nishida H., Ogawa Y., Konishi T., 2003. Prevention of oxidative injury in PC12 cells by a traditional chinese mdicine, Shengmai San, as a model of an antioxidant-based composite formula. Biological and Pharmacological Bulletin 26(7), 1000-1004.

Wentrup, C., 1984. Reactive Molecules: The Neutral Reactive Intermediates in Organic Chemistry. John Wiley and Sons, New York (Chapter 2)

Yokozawa T., Chen C.P., Dong E., Tanaka T., Nonaka G.I., Nishioka I., 1998. Study on the inhibitory effect of tannins and flavonoids against the 1,1-diphenyl-2 picrylhydrazyl radical. Biochemical Pharmacology 56(2), 213-222.

Zimmermann K.C., Bonzon C., Green D.R., 2001. The machinery of programmed cell death. Pharmacology Therapeutics 92(1), 57-70. 
Table 1. Free radical scavenging parameters of the different drugs tested.

\section{TABLE}

Different concentrations of each drug were added to the ethanolic solution of DPPH and the discoloration measured spectrophotometrically, at $517 \mathrm{~nm}$, after $40 \mathrm{~min}$. Results were expressed as the percentage of DPPH discoloration towards a positive control containing only the DPPH solution. All the drugs present $\mathrm{IC}_{50}$ values of the micromolar order, which is indicative of their high antiradical activity. The antiradical efficiency is higher for FMA5 and FMA8.

Fig. 1. Schematic structure of the newly synthesized nitrogen compounds. Two phenolic units are linked to an amidine function (Am) through a linear chain (Linear Spacer) or through a cyclic chain (Cyclic Spacer) containing one nitrogen in three carbon atoms. The compounds were prepared as described in Materials \& Methods.

Fig. 2. Dose-response curves of the $\%$ of inhibition of DPPH discoloration vs drug concentrations. The $\mathrm{IC}_{50}$ values were calculated from the represented curves, as the concentration needed to inhibit, by $50 \%$, the discoloration of DPPH. Trolox and $\alpha$-tocopherol wee used as comparison. For each concentration is represented the \pm S.E.M., considering the results obtained in, at least, three different experiments.

Fig. 3. Cellular viability assessed by the MTT reduction test and LDH release method. Trypsinized fibroblasts were plated to adhere for five hours, at $37^{\circ} \mathrm{C}$, after which the drugs were added, in a concentration five-fold greater than the $\mathrm{IC}_{50}$ previously determined by the $\mathrm{DPPH}$ discoloration method. After overnight incubation with the drugs, MTT reduction or LDH release to the extracelular medium were evaluated and, in both cases, correlated with a control of cells exposed to $1 \%$ ethanol. For each bar is represented the mean \pm S.E.M., considering the results obtained in at least three different experiments. There are no statistical differences between the compounds relatively to the control. There are also no statistical differences between the two tests used. 
Table 2. Partition coefficient (PC) and Retardation factor (Rf) values for each drug.

TABLE

PC values were measured in an n-octanol/HEPES (20mM, pH 7.4) system, and Rf values were determined by TLC. FMA4 and FMA7 present a higher liposolubility than FMA5 and FMA8. The results of PC values presented are the means \pm S.E.M. of at least three different experiments. ${ }^{*}$ Trolox and $\alpha$-tocopherol values in Nenadis et al., 2003.

Fig. 4. Comparison between L929 and PC12 cell lines, in relation to induction of lipid peroxidation. The oxidant pair used for L929 was $2 \mathrm{mM}$ ascorbate / $400 \mu \mathrm{M}$ iron (1 hour incubation), while for PC12 it was used $2 \mathrm{mM}$ ascorbate / $100 \mu \mathrm{M}$ iron (2 hours incubation). MDA production was determined by TBARS assay, and corrected for the amount of protein used in each case. For each column is represented the mean \pm S.E.M., considering the results obtained for at least 3 independent experiments. $* * * p \leq 0.001$, compared to respective control. Insert: Fibroblasts were incubated in the presence of different oxidant pairs for $1 \mathrm{~h}$. MDA production was determined as above.

Fig. 5. Relative drug protection of lipid peroxidation in PC12 cells. The oxidant pair concentration used was $2 \mathrm{mM}$ ascorbate $/ 100 \mu \mathrm{M} \mathrm{Fe}^{2+}$. Cells were pre-incubated with the drugs for 3 hours, prior to the addition of the oxidant pair, which was left for 2 hours more. For each column is represented the mean \pm S.E.M., considering the results obtained for at least 3 different experiments. ${ }^{+} p \leq 0.05,{ }^{++} p \leq 0.001$, compared to the respective concentration of $\alpha$-tocopherol. ${ }^{\#} p \leq 0.05$, compared to the lower concentration of the same compound.

Fig. 6. Evaluation of caspase-3 activity in PC12 cells. Cells were incubated with $1 \mu \mathrm{M}$ STS, for 5 hours. A: Cells were incubated simultaneously with the compounds and STS B: Cells pre-incubated in the presence of the compounds for 3 hours before the addition of STS. For each column is represented the mean \pm S.E.M., considering the results obtained in at least 3 different experiments. $* p \leq 0.05$, compared with $1 \mu \mathrm{M} \mathrm{STS} ;{ }^{+++} p \leq 0.001$, compared to control with cells only. 
Fig. 7. Evaluation of the new drugs protective effect in the apoptotic pathways mediated by caspases 3,8 and 9 in PC12 cells. Cells were pre-incubated with the compounds for 3 hours. The activities of the enzymes were induced with $2 \mu \mathrm{M}$ STS for 5 hours. Results are expressed as the increase in each substrate cleavage, relatively to the control. For each column is represented the mean \pm S.E.M., considering the results obtained in at least 3 different experiments. ${ }^{+} p \leq 0.05$, compared with STS-treated cells; ${ }^{+} p \leq 0.05$, ${ }^{+++} p \leq 0.001$, compared to control cells.

Fig. 8. Chromatin condensation analysis in PC12 cell line. FMA7 was added to the cells 3 hours prior to the addition of STS $1 \mu \mathrm{M}$. A, B: control; C, D: 5-hour treatment with STS $1 \mu \mathrm{M}$; E, F: FMA7 $20.4 \mu \mathrm{M}$; G, H: FMA7 $40.8 \mu \mathrm{M}$; A, C, E and G: cells stained with Hoechst 33342; B, D, F and H: Hoechst 33342 / propidium iodide (PI) double staining. The nuclei were counted according to their morphology and specific label. The filled arrows point out to necrotic cells, while the dashed arrows indicate apoptotic cells. Images A, B, G and $\mathrm{H}$ are magnified 63x, while images $\mathrm{C}, \mathrm{D}, \mathrm{E}$ and $\mathrm{F}$ are magnified 160x.

Fig. 9. Graphical representation of Hoechst positive and PI positive cells after exposure to STS and FMA7. Experimental conditions are the same as in Fig. 8. For each column is represented the mean \pm S.E.M., considering the cell counting in at least 3 different experiments. ${ }^{*} p \leq 0.05,{ }^{*} p \leq 0.01$, compared with 1 $\mu \mathrm{M} \mathrm{STS} ;{ }^{++} p \leq 0.01$, compared to respective control.

Fig. 10. Lipid peroxidation levels obtained for the cyclic compounds. PC12 cells were incubated with the cyclic compounds in the same conditions as the linear chain compounds. A: In the presence of the oxidant pair $2 \mathrm{mM}$ ascorbate $/ 100 \mu \mathrm{M} \mathrm{Fe}^{2+}$; B: in the absence of the oxidant pair. For each column is represented the mean \pm S.E.M., considering the results obtained for at least 3 different experiments. ${ }^{*} p \leq 0.05,{ }^{* *} p \leq$ $0.01, * * * p \leq 0.001$, compared to control. 


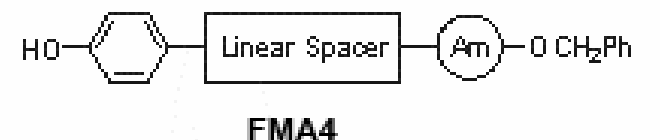

FMA4

Ho- $-\mathrm{Am}-\mathrm{OCH}_{3}$

FMA7

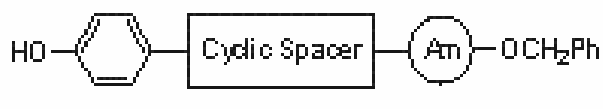

FMA698
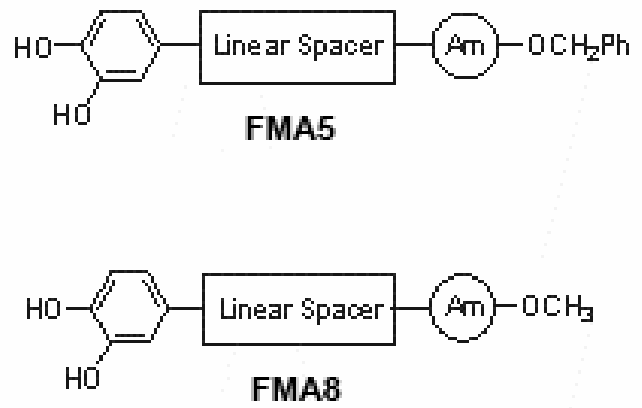

$\mathrm{HO}-\mathrm{A}-\mathrm{Am}-\mathrm{OCH}_{3}$

FMA699

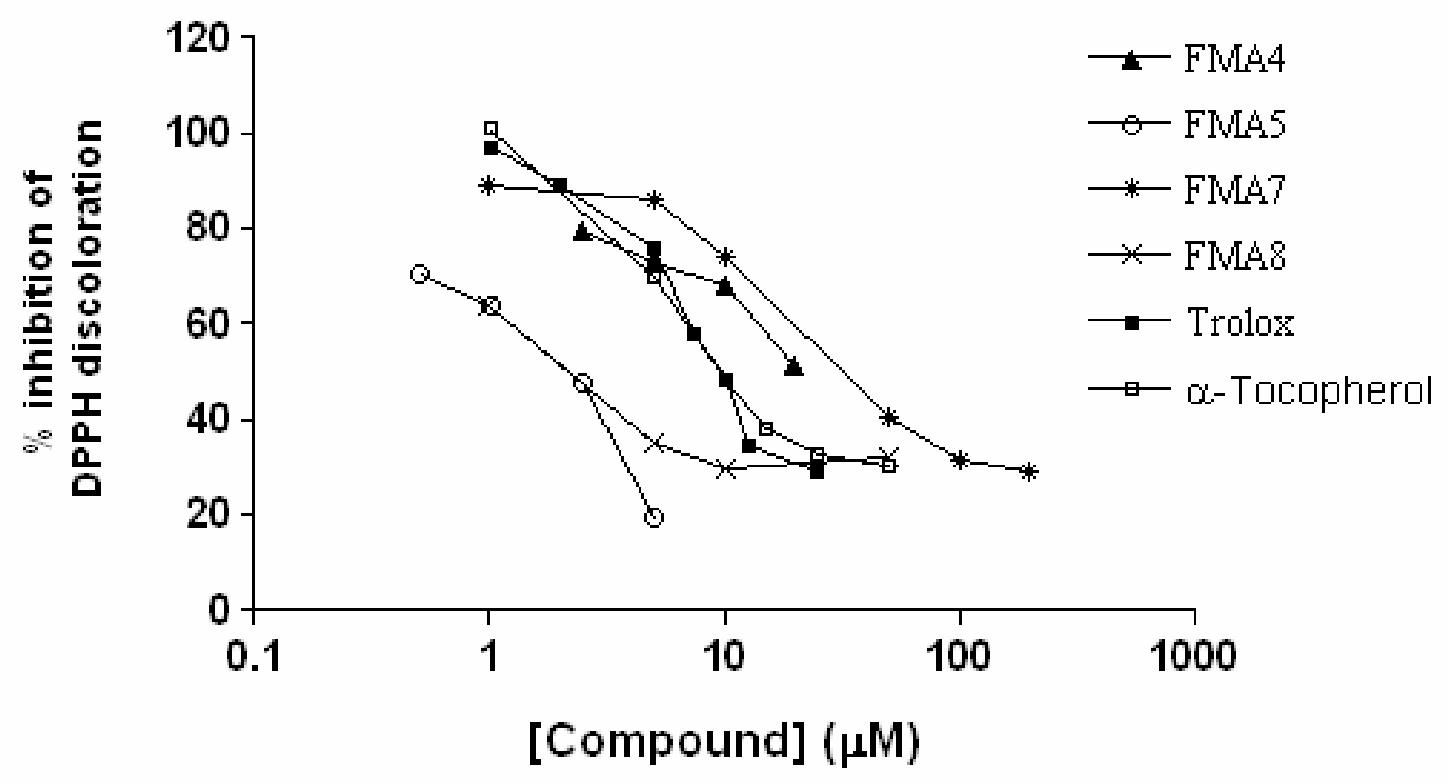



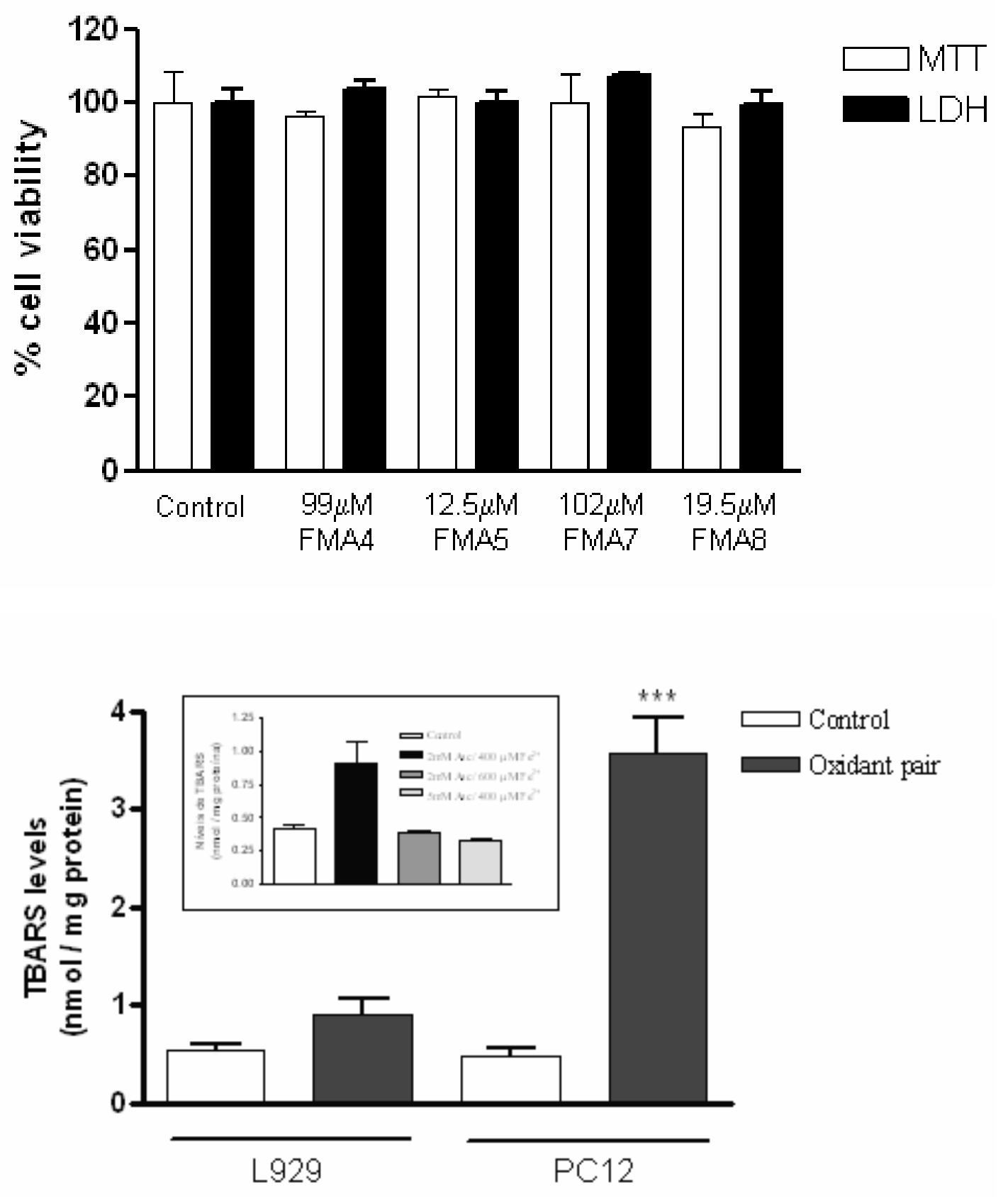


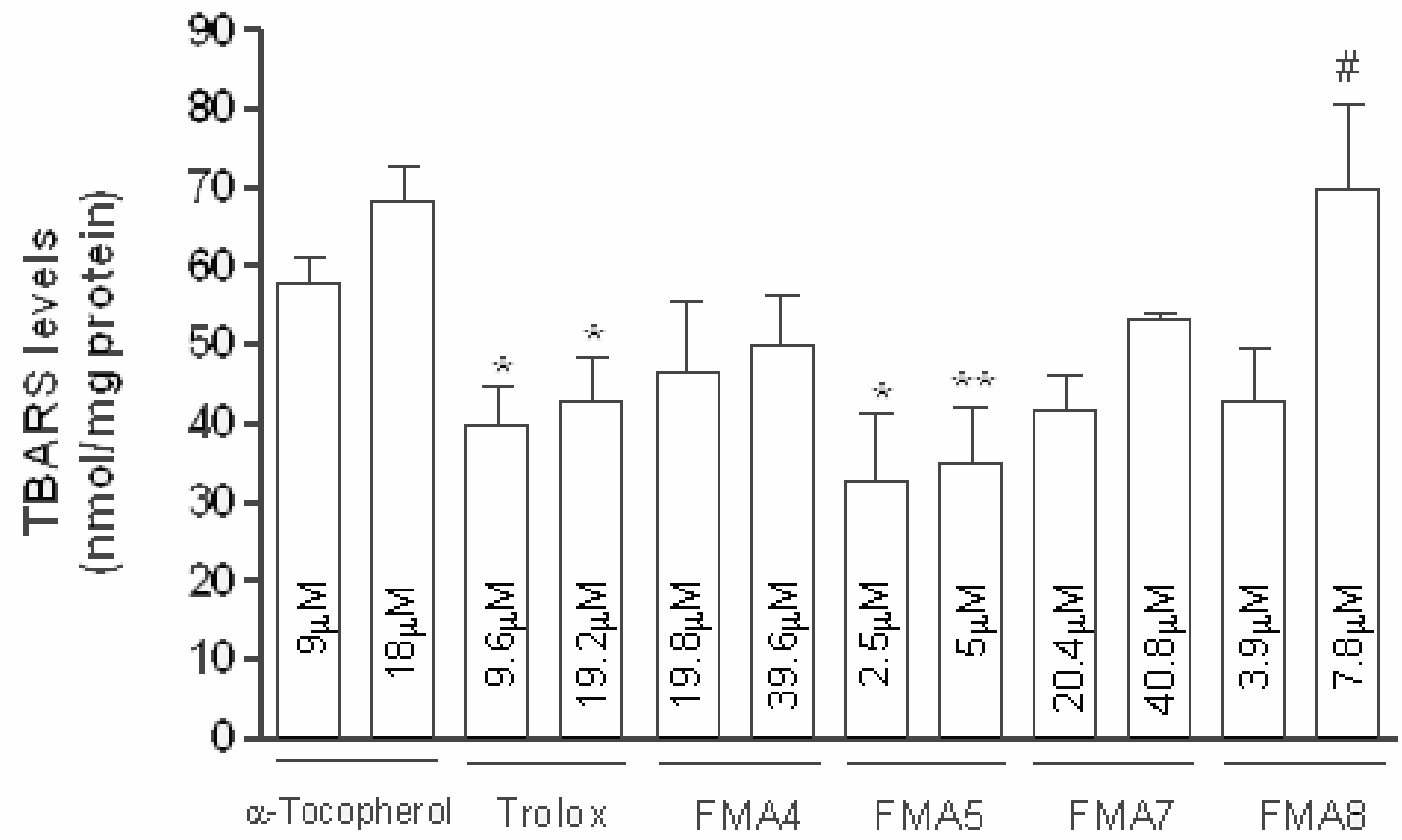




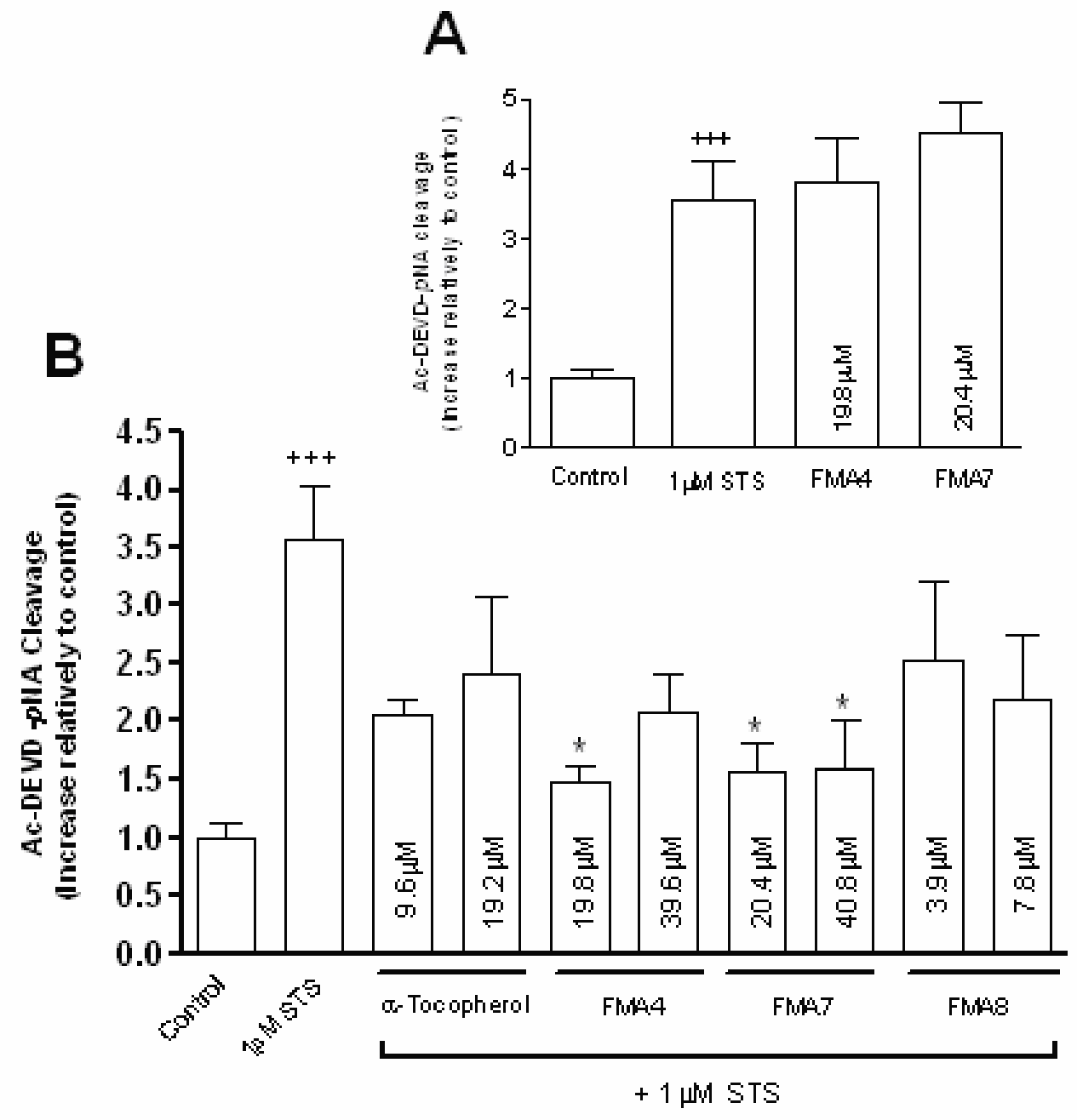


A

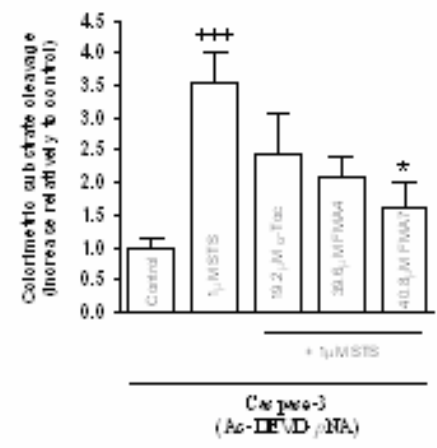

B

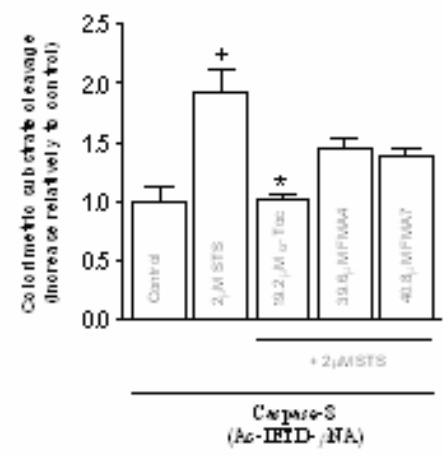

\section{C}

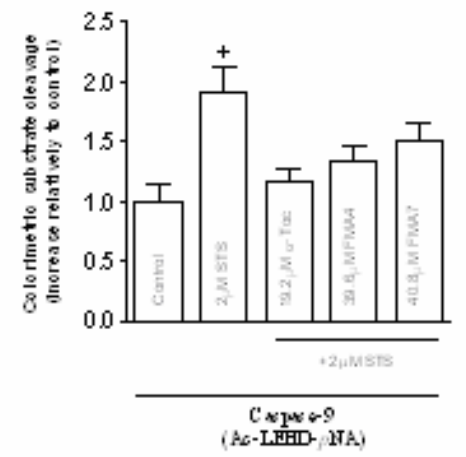



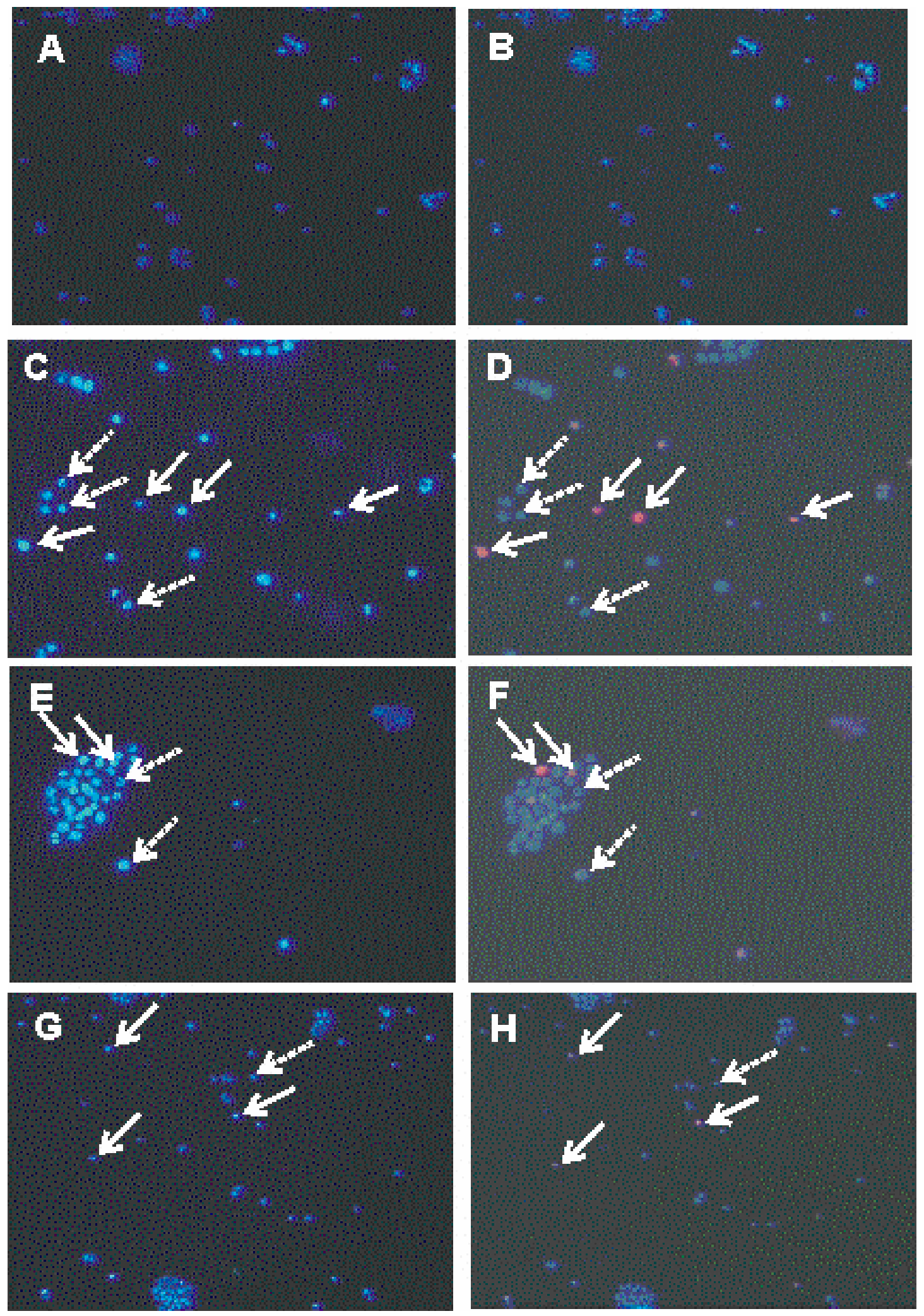


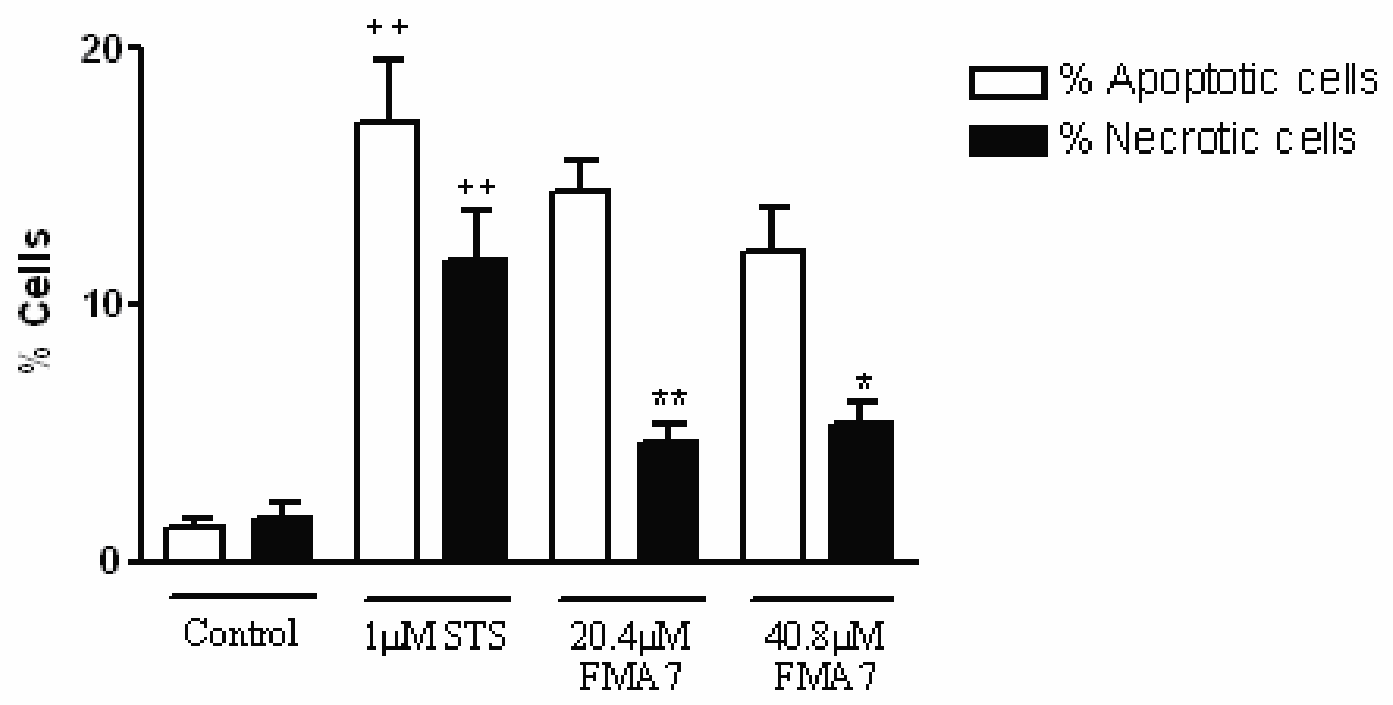

\begin{tabular}{cccc}
\hline Drug & $\mathbf{I C}_{\mathbf{5 0}}(\boldsymbol{\mu M})$ & $\mathbf{T}_{\text {IC50 }}(\mathbf{m i n})$ & $\begin{array}{c}\text { Antiradical } \\
\text { efficiency }\left(\mathbf{1 0} \mathbf{~ 1 0}^{\mathbf{3}}\right)\end{array}$ \\
\hline FMA4 & 19.8 & 40 & 1.26 \\
FMA5 & 2.5 & 20 & 20.00 \\
FMA7 & 20.4 & 40 & 1.23 \\
FMA8 & 3.9 & 20 & 12.82 \\
Trolox & 9.0 & 20 & 5.56 \\
Q-Tocopherol & 9.6 & 40 & 2.60 \\
\hline
\end{tabular}




\begin{tabular}{ccc}
\hline Drug & PC values & Rf values \\
\hline FMA4 & $1.65 \pm 0.13$ & 0.67 \\
FMA5 & $1.31 \pm 0.13$ & 0.40 \\
FMA7 & $1.42 \pm 0.03$ & 0.58 \\
FMA8 & $0.68 \pm 0.03$ & 0.36 \\
Trolox & $0.49 \pm 0.02\left(^{*}\right)$ & $\ldots$ \\
$\alpha$-tocopherol & $6.76 \pm 0.39\left(^{*}\right)$ & $\cdots$ \\
\hline
\end{tabular}

A
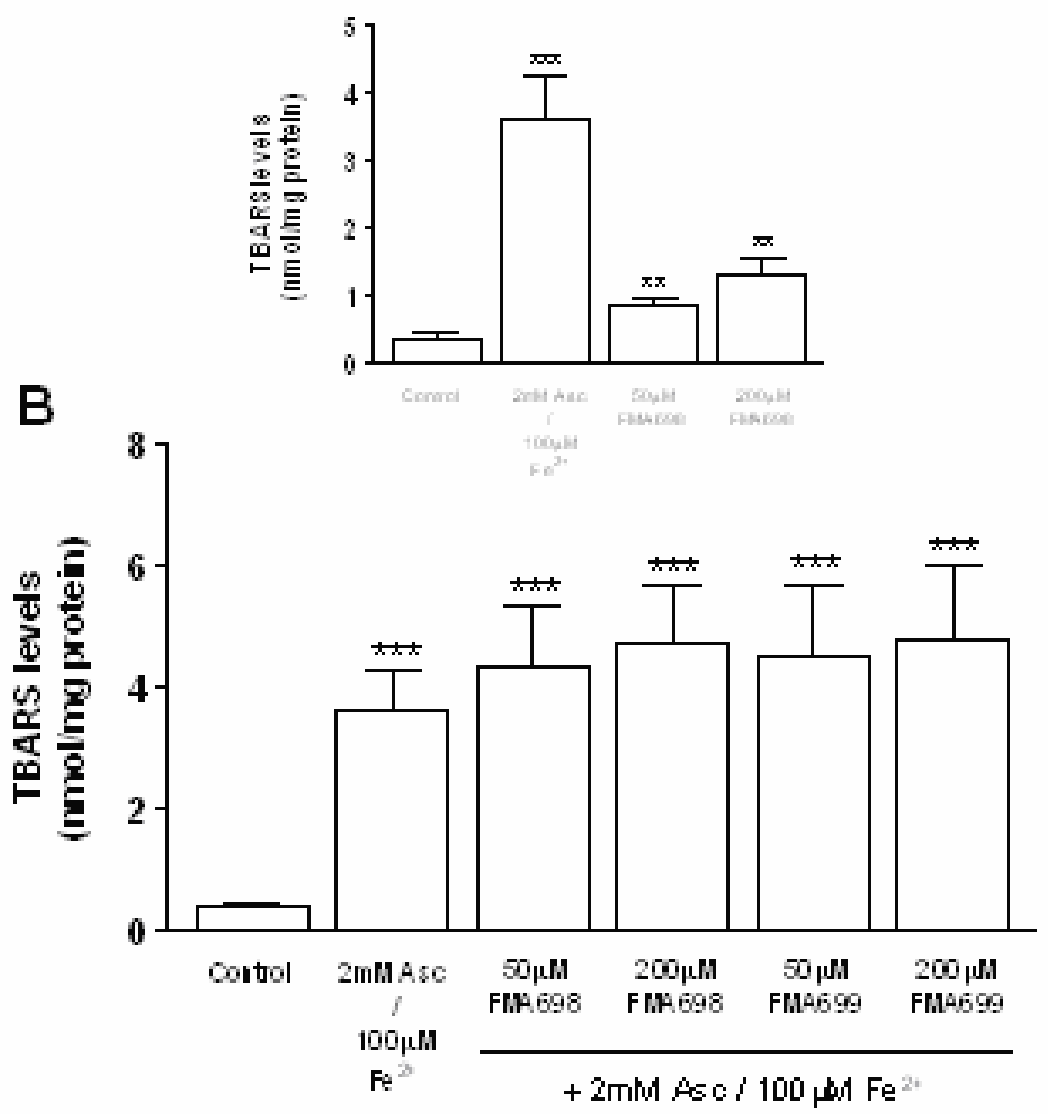
